\title{
Technology, Research and Applications of Switched Reluctance Drives
}

\author{
Bernhard Burkhart, Annegret Klein-Hessling, Iliya Ralev, Claude P. Weiss, \\ and Rik W. De Doncker
}

\begin{abstract}
Electrical drives are one of the major consumers of electrical energy and their penetration in the market is still growing. Hence, for many drive applications efficient, reliable and cost effective solutions have to be found. Switched reluctance drives (SRD) offer a potential solution when focus is mainly on cost and robustness. However, to benefit from the unique advantages of this machine type a deep understanding of its strongly non-linear behavior is required. After discussing some major differences to classic rotating field machines, this paper presents a broad overview of the state of the art of SRD taking into consideration all aspects relevant to machine modeling, design and control development process. Finally, applications on the market utilizing SRDs and the focus of current research is presented. After reading this paper the reader will be able to assess if this modern drive technology could be advantagous in a given application.
\end{abstract}

Index Terms-Switched reluctance drives, switched reluctance machine, design, modeling, analysis, control, acoustics.

\section{INTRODUCTION}

A LTHOUGH the switched reluctance machine (SRM) is one of the oldest rotating machine concepts (proposed first by Taylor in 1840 [1]), its practical implementation and market introduction came to fruition in the mid-1980's thanks to the development of modern power electronic components and control circuitry [2]. The SRM has always been of interest to drive designers due to its simple working principle and robust mechanical construction. Especially, for high-speed applications with low-to-medium torque requirements, or when a high overload capability is necessary, the SRM has unique advantages over classic rotating field machines. However, due to the SRM's highly non-linear characteristics, the design of a switched reluctance drive (SRD) requires an integrated, often iterative, design process in which the converter, its controls and the design of the SRM itself are intertwined. Hence, a global system perspective of the SRD technology is essential to reach an appropriate solution for the target application. To achieve this task a fundamental understanding of the entire SRD, i.e. the machine, its inverter (including control) and the target system are required.

Within this paper state-of-the-art and current research on

Manuscript received March 24, 2017.

All Authors are with the Institute for Power Electronics and Electrical Drives, RWTH Aachen University,Jaegerstr.17-19,52066, Aachen, Germany (e-mail: post@isea.rwthaachen.de).

Digital Object Identifier 10.24295/CPSSTPEA.2017.00003
SRD will be covered. Section II compares the SRD to itsrivals, the synchronous and induction machines. Thereafter, design approaches are presented in section III, followed in section IV and V by SRD modeling and analysis techniques. The technological discussion closes with the inverter and its control in section VI and VII. In section VIII some examples of SRDs available on the market are presented and discussed. Finally, an overview on current application research is given.

\section{Pros AND Cons of SRDs}

The outcome of selecting the optimal drive for a given application depends strongly on the application's requirements, i.e. torque and speed, and the design goals. Selecting a certain machine or designing an electrical drive is generally a compromise between technologically conflicting requirements, such as power density, efficiency (in a single operating point or over an entire load cycle), field-weakening potential, cost, employed materials, machine or drive volume, fault tolerance and maintenance cost. This section highlights some major differences between various machine types with respect to these requirements.

Beside machines with permanent magnets, all electrical machines have in common, that the primary flux has to be supplied by an external source. Thereby, as long as no field-weakening is required, permanent magnet synchronous machines (PMSM) tend to have the lowest ohmic and inverter losses, and therefore the highest overall system efficiency in the so-called base speed region. However, when using surface mounted permanent magnets (SPMSM), only a very small field-weakening operation, similar to synchronous reluctance machines (SynRM), is possible. A common figure of merit is the field-weakening (maximum speed compared to the corner speed ) of the machine. In case of SynRMs this ratio is about 2.5 [3]. Switching to interior permanent magnet machines (IPMSM) and adding a certain amount of reluctance torque, the field-weakening ratio can be pushed up to 5-7 times its corner speed. In contrast to the variable flux machines, this operation however forces the inverter to supply reactive current to actively weaken the magnet flux and hence reduce the efficiency. Induction machines (IM) have higher rotor losses when compared to SynRM and hence generally a lower efficiency region. However, the IM has a larger field-weakening area with 3.5 to 5 times its corner speed [4]. A major disadvantage for applications with special sizing requirements is the fact that the IM is the only 
machine which can not be effectively built with concentrated windings that have shorter end-turns compared to distributed windings.

For SRMs an extensive field-weakening area, up to 10 times, is claimed [5]. This wide speed range capability originates from the possibility to operate the SRM in deep magnetic saturation. Furthermore, single-pulse operation enables exciting the SRM far above the designed corner speed point. Both features combined offer even an additional overload reserve above base speed when the machine is operated in continuous conduction mode (CCM). The efficiency of SRMs is similar to that of a SynRM in the designed operating region, however the rotor losses are expected to be higher due to the pulsating magnetic fields. In contrast to IPMSMs, the efficiency of SRMs is the highest in the region just above base speed and at high torque. Hence, SRMs are especially suited for applications with a broad field-weakening region. On the other hand, at partial load some penalty has to be expected.

SRMs are operated with pulsating voltage or current waveforms. These block waveforms cause significant pulsating forces between rotor and stator. Particularly the radial forces, which are much larger than the tangential forces, cause vibrations and therefore also acoustic noise [6]. The steeper flanks of the force waveforms in SRMs (compared to rotating field machines) are disadvantageous to reduce noise, which can only be reduced to a certain extent by proper machine design, housing construction or force control measures [7], [8]. Similarly, the inherent torque ripple has to be tackled during the design stage and can be reduced further with appropriate torque control methods. Possible solutions to reduces these disadvantages are presented in sections III and VII in this paper.

Regarding thermal design of electrical machines, e.g. for temperature critical applications, the SRM as well as the SynRM are particularly suitable for high temperature applications. The maximum operating temperature of these machines is only limited by the thermal insulation class used for their windings. In contrast to this, in IPMSM and SPMSM the employed magnet material, as well as eddy current losses in the rotor place serious constraints on the maximum temperature at which these machines can be operated. In IMs the thermal expansion coefficient of the rotor cage and electric sheet materials have to be considered for lifetime estimations due to mechanical stress during thermal cycling.

The low rotor inertia, high torque dynamics as well as the lack of drag torque in freewheeling are further benefits of the SRM compared to rotating field machines. The high torque dynamics are based on the fact that within each voltage period the entire coil is magnetized and demagnetized. Hence, for each electrical period the magnetic flux can be freely set. The time constant associated with this magnetization process is much lower than the reacting magnetizing time constant common in rotating field machines. Furthermore, the fact that the stator phases are magnetically decoupled in SRMs, makes the SRM attractive, e.g. for aerospace applications that require very high reliability [9]. Indeed, SRMs can continue operation, albeit with reduced power, when one or more phases drop out. This "limb home" capability can be of great value in traction and electrical propulsion drives for electric vehicles.

\section{DESIGN}

A long list of publications can be found, e.g. [2], [10]-[13], which present torque production equations similar to those of classic rotating field machines and analytical sizing rules for SRMs. All this work directly and indirectly contributed to a design tool developed by a team under guidance of Prof. T. Miller [14], which is till today the reference in analytical SRM design.

With the increased use of finite element analysis (FEA) other approaches, such as in [15], focus more on the physical working principal of SRMs for the design methodology. This work, based on a generalized SRM model, is further developed into a comprehensive design procedure in [16], [17]. To make the design process dependent only on physical and geometric parameters rather than empirical tuning factors a solution space based design approach is prefered in [18]. In this approach the application dependent design parameters are decoupled from the basic torque production capability of a specific SRM cross section. The underlying solution space is subdivided by the machine configuration, diameter and the coil-to-slot-ratio CTSR ([16]), which unambiguously describes the shape of stator teeth and yoke (see Fig. 1). The torque production capability is then pre-calculated by FEA and stored in a database. The design comparison can be performed with a small amount of physical parameters. As a result, the designer has a fast, yet accurate evaluation tool, based on FEA validated machine characteristics, to assess the potential and limitations of different machine configurations before entering a detailed iterative optimization process. It is shown in [18] that even in this early design stage it is essential to consider the thermal behavior and the losses,

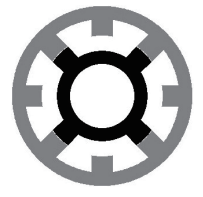

(a) $C T S R_{1}=0.60$

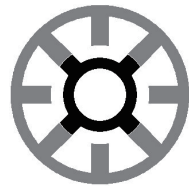

(b) $C T S R_{2}=0.65$

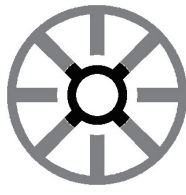

(c) $\operatorname{CTSR}_{3}=0.70$

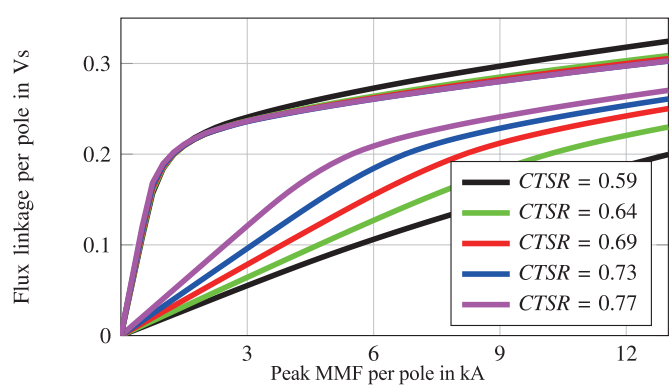

(d) Flux-linkage curves for aligned and unaligned position

Fig. 1. Influence of the CTSR on SRM cross section and flux linkage with constant outer diameter [18]. 
as the heat transfer characteristic from coil to cooling sleeve strongly depends on the SRM cross section.

Optimizing an SRM for a certain driving-cycle is a quite challenging task and strongly depends on the optimization criteria [19], [20]. If focus is mainly on efficiency, iron and eddy current losses in the coils are the main challenge. Low loss electrical steel [21] or special winding schemes and placements [22] should be considered for improvement. When focus is on acoustics, the positioning of the eigenfrequencies and the structural stiffness of the stator are of special interest. Many publications investigate the possibilities to reduce stator surface vibrations [20], [23], however interactions with control algorithms always need to be considered (see section VII).

Recent publications divert from the classic SRM structure to adopt the SRM for special applications. References [24], [25] propose a segmental rotor structure to improve the magnetic utilization and hence increase torque output. A $40 \%$ increase of power density is claimed. In [26] a double stator structure is proposed, where basically a outer- and inner-rotor SRM is combined in one machine. Beside the immense increase in torque density, an improved acoustic behavior is achieved. For the same torque, the radial forces on the outer stator are strongly reduced. In [17] an axial segmentation of a threephase machine is proposed for applications with an extremely low machine diameter requirement. These examples illustrate that the SRM concept lends itself to be adopted to new applications, thereby outperforming other machine types.

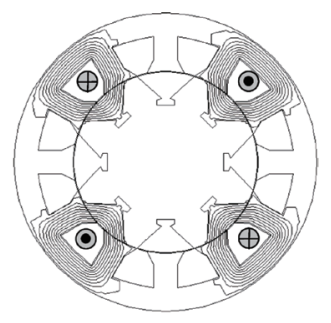

(a) Segmental rotor [25]

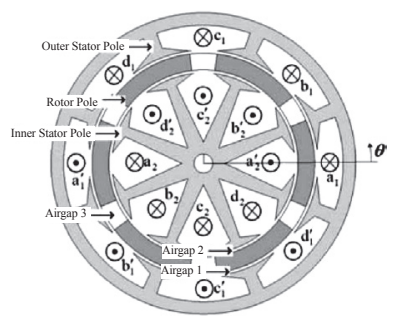

(b) Double stator [26]
Fig. 2. Special machine cross sections derived from the basic SRM functionality.

\section{MODELING}

Models for switched reluctance machines are needed for motor design and control algorithm development. To reduce development costs, system simulations nowadays are crucial in gathering and analyzing data on entire drive trains before building the actual prototype. Coupling the machine model with inverter and load models allows fast and efficient programming of control algorithms. Such simulation models are referred to as offline models and should portray reality accurately.

The second category of models are real-time online models for motor control units. Over the last decades online model complexity and accuracy has greatly increased thanks to the progress in microelectronics and its computational power.

Nevertheless, due to the strong non-linear behavior of SRMs a trade-off between simulation accuracy and simulation speed still has to be made. Some modeling techniques are very accurate but time consuming, such as the coupled finite element analysis (FEA). On the other hand, models based on analytical formulae and look-up-tables (LUTs) are very fast but tend to have reduced accuracy.

SRM models can further be divided into inductance (current fed) and flux-linkage (voltage fed) based models, depending on the main state variable. Commonly the machine's phase voltage equation, integrating the terminal voltage, is used to calculate the flux linkage per phase. The non-linear transformation of the phase flux linkage at a certain rotor position to the produced torque (radial forces and phase current) can be modeled by a number of different approaches in an attempt to combine simulation accuracy and speed. These techniques are described in the next sections..

\section{A. Offline: SRM Models for System Simulations}

Today, look-up tables (LUT) are most common to model SRMs, as they are directly transferable to the controller of the machine. Thereby, the relationship between flux linkage, rotor position, current and torque is stored in 2D LUTs. As switched reluctance machines are operated in saturation, it is important to consider their non-linear magnetic characteristics. This is achieved by non-linear FEA simulations [22] or testbench measurement of the actual machine [27]-[29].

Depending on the winding configuration an inductance (Fig. 3) or flux based (Fig. 4) machine model can be more suitable. When series windings are considered, the inductance based modeling approach is more suitable. In case parallel windings are considered, a flux-linkage based modeling approach is more suitable. Normally phase based LUT models are used. However, if machine asymmetries, for example rotor eccentricities, are simulated, the models should be pole based so that each stator pole has its own LUT.

The computationally fastest models are analytical formulas describing the electro-magnetic SRM behavior as in [27], [30]-[33]. Thereby, the analytical equations describe the

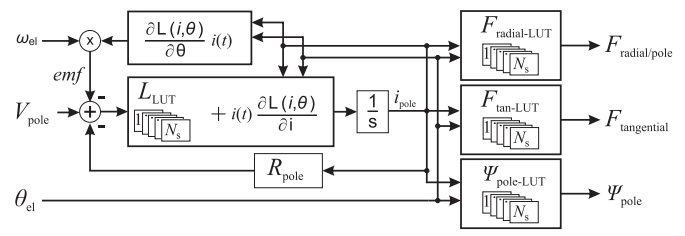

Fig. 3. Per pole inductance (current) based look-up table SRM model.

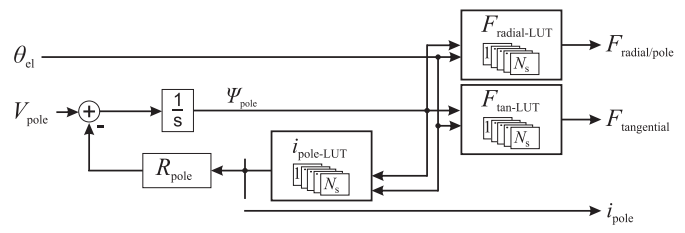

Fig. 4. Per pole flux-linkage based look-up table SRM model. 
machine geometry, to determine the flux path through the machine, with focus on the air gap. From the magnetic flux distribution the tangential- and radial forces are determined. Alternatively, equations can be expressed to fit the non-linear phase inductance of the SRM. The model thus becomes an inductance based model, describing the change of the inductance in dependence of rotor position and current.

Similar to analytical equations describing the flux path, magnetic lumped parameter models known as magnetic equivalent circuits (MECs) can be used. In contrast to the analyticaland LUT models, MEC models are more commonly used when phase coupling [34], [35] or geometric asymmetry effects in the machine are described [36], [37]. MECbased models offer a more sophisticated machine model, with more accuracy compared to analytical models, without the computational complexity of a FEA. MEC networks can either be formulated as meshes or nodes, resulting in different matrices to be solved. A comparison is investigated in [38].

With the advances of computer aided design FEA software tools specifically for electrical machines have become available. Not only are non-linear machine characteristics being calculated to support the design process of electrical machines, also in-depth electromagnetic and multi-physics analysis has become possible. Calculating the flux distribution, eigenfrequencies and forces acting on the machine during the design process has become state-of-the-art. A further method to analyze SRMs are circuit coupled FEA models. Thereby, a time-stepping simulation is executed modeling the inverter and control circuit with a circuit simulator, while the actual crosssection of the machine is modeled in great detail with FEA, and the control algorithms are executed for example in MATLAB/Simulink. This allows loss distribution analysis (eddy current, iron loss) at a specific operating point determined by its specific current trajectory. The disadvantage of coupled-FEA is the computational complexity and considerably longer computational time [39]. In pancake shaped machines the effects of end windings can be considerable. Calculating stray flux due to end effects is only possible with 3D FEA. However, the meshing complexity increases manifold compared to a $2 \mathrm{D}$ analysis, leading to even longer computation times.

The challenge to reduce computation complexity while maintaining the most realistic model has sparked the search for different kinds of machine modeling approaches. Nakamura models iron loss within a MEC model by incorporating additional inductances next to the reluctances [40]. Another approach for offline and online modeling to calculate instantaneous torque are gage curves [30], [32]. Thereby, the flux-linkage versus rotor position and current characteristic is stored as normalized flux-linkage curves in relation to the rotor position in a LUT. This allows instantaneous torque calculation at a constant current from differentiation of the stored flux linkage values.

\section{B. Online: SRM Models for Real-Time}

When designing online models the main challenge is to create algorithms with high accuracy that are able to run in real-time on (low-cost) motor control units. Today, often a LUT-based approach is used, whereby the tables are provided by either FEA or measurements. To reduce the initialization effort and to account for production uncertainties, the amount of auto-parameterizing [41], genetic algorithms, self-learning and neural network tuning algorithms, that adjust the characteristic stored in the LUT to the actual machine, has increased steadily.

Alternatively, to model saturation and phase coupling in an SRM, Fleming proposes to use MEC-based models [42], [43]. However, the network needs to be reduced to enable realtime capability, leading to a strongly reduced analytical phase model.

\section{Analysis TeChNiQues}

\section{A. Losses}

To predict efficiency of a particular SRM design or a control strategy, the machine losses need to be determined already at an early development stage. Machine losses in general are divided into copper losses, iron losses and mechanical friction losses.

Copper losses consist of ohmic losses and additional eddy current losses caused by the skin and proximity effects. Contrary to conventional rotating field machines, the windings of SRMs are penetrated by a high amount of stray flux at the stator tips. Therefore, for an accurate efficiency analysis eddy currents in the windings have to be considered [22], [39], [44]. The amount of stray flux depends on the saturation of the stator teeth. The saturation leads to nonlinear magnetic behavior. Additionally, the stray field is two-dimensional and varies depending on the position of the rotor [22]. In most cases analytical approaches are not sufficient for copper loss calculations of SRMs. In [39], [44] an automated copper loss analysis based on FEA is presented.

The approach from [39] considers the actual phase current trajectory to determine the instantaneous losses $\left(p_{v}\right)$ depending on the electrical position of the rotor. Fig. 5(a) displays the copper losses of a four-phase SRM operated with hysteresis current control. During motoring operation, the winding losses on the leading side of the stator teeth are higher than the losses on the trailing side. This is due to the fact that the magnetization of the phase before the aligned position causes a higher amount of stray flux penetrating the leading side windings.

The instantaneous ohmic losses $\left(p_{v, \mathrm{dc}}\right)$ depend quadratic on the phase current and account in the observed case only for a small amount of the copper losses. Eddy current losses occur also due to magnetization of the neighboring phases. Fig. 5 (b) shows the loss distribution depending on the position of each winding in the coil. In windings closer to the air gap higher eddy currents are induced.

For the iron loss estimation in electrical machines various methods and models are presented in literature. Two 
groups can be distinguished: empirical models and physics based models [45]-[47]. Empirical models base on equations deduced from measurements as e.g. the original Steinmetz equation (OGE) [48]. The Jiles-Atherton model [49] is an example for a physics based approach. The model describes the losses based on the molecular behavior of the material.

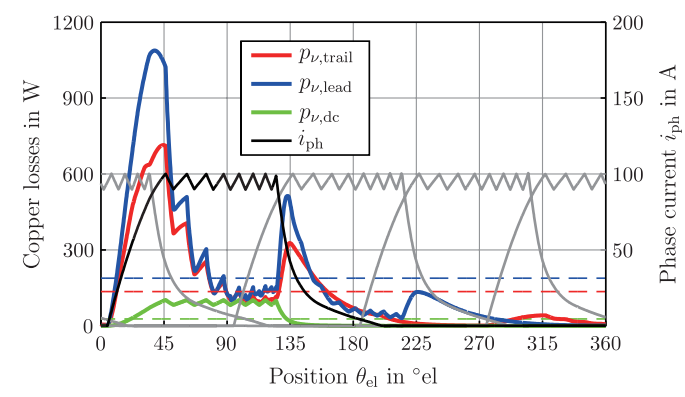

(a) Losses depending on the electrical position

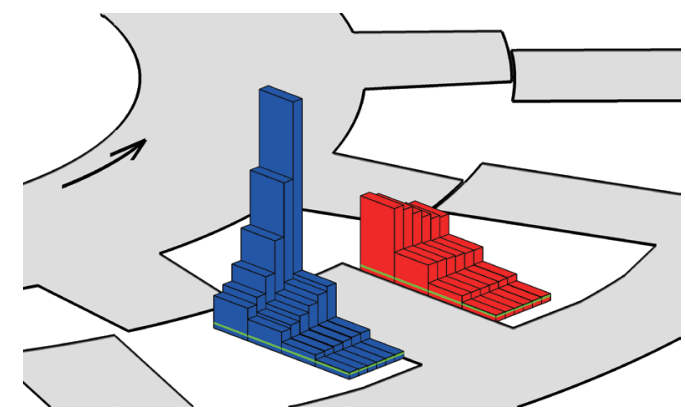

(b) Loss distribution depending on the position of the winding

Fig. 5. Finite-element based winding loss calculation [22].

The flux in SRMs is non-sinusoidal. Therefore, approaches considering the time-depending gradient of the flux density instead of the peak flux density are more applicable for SRMs, e.g. modified Steinmetz equation (MSE) [50] and the improved generalized Steinmetz equation (iGSE) [51]. For the loss calculation with analytical approaches the SRM is divided into parts (e.g. stator teeth and stator yoke sections) assuming a homogeneous flux density in each of this part [52]. However, especially at the tips of the teeth this assumption is not fulfilled due to deep saturation. The choice between an analytical approach and an FEA is a trade-off between accuracy and calculation effort.

Fig. 6 exemplifies a loss distribution of a two-phase SRM based on an FEA [47]. Due to the symmetry of the machine only a quarter of the machine is investigated. The dissimilar distribution of the losses along the stator yoke (points a and $b$ ) can be observed. The reason for this is that some yoke segments experience an alternating magnetic flux, while others segments experience only an unidirectional flux. The effect is typical for SRMs. Furthermore, the loss density is higher at the tips of the teeth (points $\mathrm{d}$ and g) as in middle of the teeth (points $\mathrm{c}$ and $\mathrm{f}$ ) as shown in Fig. 6.

Mechanical friction losses occur in every machine. However, due to the doubly salient structure of the rotor and the stator, SRMs are prone to higher windage losses. Especially at high rotational speeds, the windage losses in the air gap should be minimized. These losses can be estimated with the formulas proposed in [53], which are also implemented in [14]. References [54], [55] confirm the losses with some experimental results.

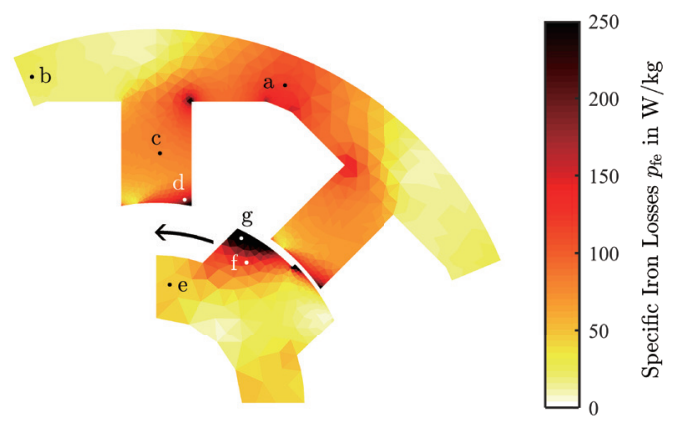

Fig. 6. Loss distribution of an two-phase 8/4 SRM [47].

\section{B. Thermal Behavior}

Improved power density of electrical machines is achieved by downsizing and pushing the machines towards their thermal limits. However, overheating reduces the life span of the machines and might cause premature failures [56]. Therefore, it is important to analyze the thermal behavior of the machine and the effect of the occurring losses on the machine regarding the resulting temperature distribution.

To model the thermal behavior of SRMs, lumped parameter thermal networks (LPTNs) [57] or computational fluid dynamics (CFDs) and FEAs [58] are used. Space-resolved lumped parameter thermal networks have been proposed to predict the hot-spot temperature as well as the temperature at any userspecified spot within the machine [59]-[62]. They represent a trade-off between accuracy and calculation effort.

The space-resolved LPTNs of electrical machines are based on 3D cylindrical elements. Each element consists of three 1D T-structure thermal circuits connected at their central points (Fig. 7(a)). The resistances represent the thermal contacts and conductivity while the capacitor represents the thermal capacity of the object. The losses of the element are fed into the element by the current source. The potential of the central node represents the average temperature of the element. The potential of the outer nodes represents the temperatures on the boundary surfaces [60].

The LPTN can often be simplified using the angular symmetry of the machine. The minimum symmetry of SRMs is

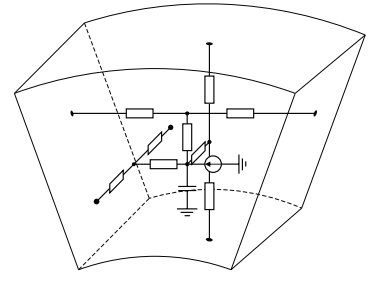

(a) Cylindrical element

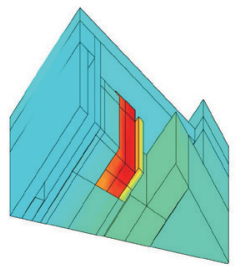

(b) Discretization
Fig. 7. Space-resolved lumped parameter thermal network [56]. 
one half of a stator tooth and one half of a rotor tooth [56]. Fig. 7(b) shows the discretization of an 18/12 SRM. Implemented on a controller the space-resolved LPTN can be used to estimate the temperatures of the machine online. This information can be used for model predictive overload control of electrical machines [63].

\section{Acoustic Excitation}

Noise in electrical machines is of electromechanical (radial force ripple, torque ripple, inverter switching), mechanical (bearings, friction), combined electrical and mechanical (eccentricity) or aerodynamic (fan, rotor) origin [6], [64], [65]. For SRMs the acoustic noise of electromagnetic origin dominates the aerodynamic noise except in case of high-speed SRMs with open rotors [66]. The most relevant source is the airgap force [6], which is hard to measure directly but can be determined via simulations of the electromagnetic domain from its excitation (current, magnets). The air-gap force is transformed via the structure domain to vibrations which are transmitted via the acoustic domain to airborne sound [65]. Classical acoustic machine models simulate this causal path as a three-domain approach [67].

As shown in Fig. 8(a), the time-dependent radial air-gap force can be decomposed to spatial Fourier series components, socalled force shapes (FSs). The Fourier series can eventually be truncated based on the observation that with increasing spatial order $v$ the vibration response of the machine to a force excitation shape decreases [67]. Due to the symmetry of SRMs along the axial direction only the forces in 2D need to be considered [65].

Analog to the spatial force decomposition, the timedependent deflection of the SRM can be described by a superposition of modes [69] (Fig. 8(b)). The modal superposition approach is based on the fact that the dynamic behavior of a structure for a given frequency range can be separately modeled as a set of individual modes of vibration [65]. Modes are almost exclusively excited by force shapes with the same order [70]. The excitation of a mode due to a force shape is

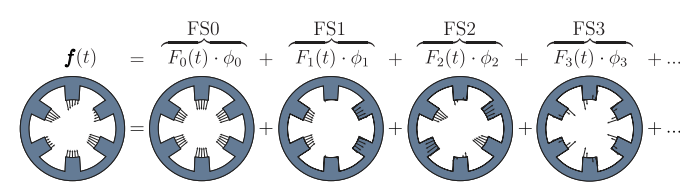

(a) Spatial force decomposition

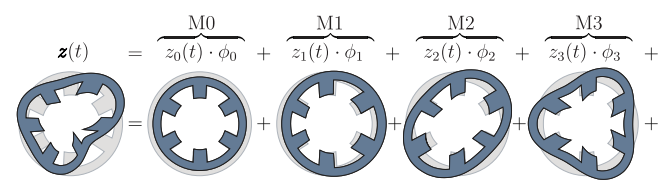

(b) Modal superposition

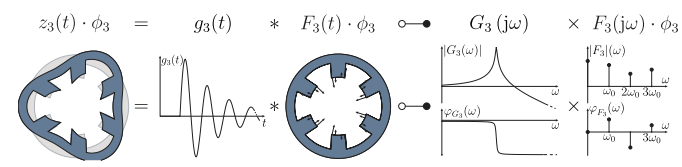

(c) Vibration synthesis quantized by the structural vibration response $g_{\nu}$. A transformation of the vibration response and the force shape to the frequency domain simplifies the calculation (Fig. 8(c)). Additionally, the eigenfrequency of the vibration response becomes visible.

A universal acoustic modeling framework for electrical machines is introduced in [65], [71]. The structure of the framework is shown in Fig. 9. The normalized structural responses and the electromagnetic characterizations including the air-gap force model are pre-calculated with two independent FEAs. The data is saved and can be used afterwards. For each operating point or torque-speed trajectory a system simulation calculates, with help of the stored FEA-data, the occurring force shapes. With these force shapes and the stored vibration responses the vibration synthesis determines the resulting machine vibrations.

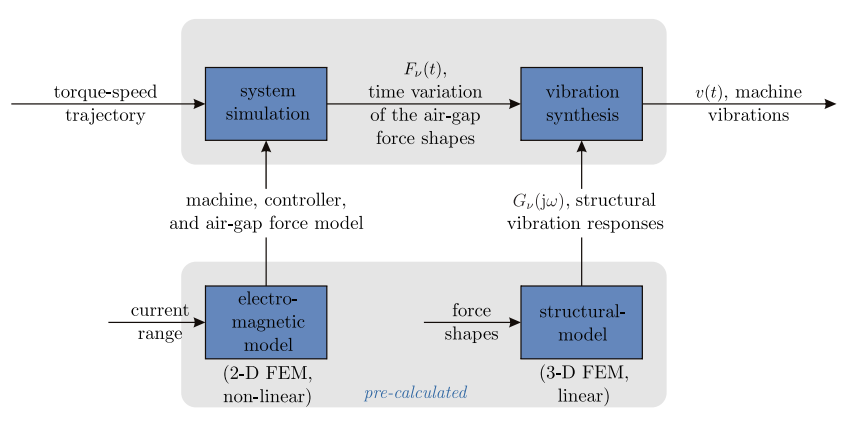

Fig. 9. Acoustic modeling framework [65].

The advantage of this approach is that the two FEAs with high calculation effort have to be carried out only once per machine design. This results in high accuracy and low calculation effort. In comparison, for the classic threedomain approach [67] for each operating point all three models have to be solved. This creates a trade-off between fast and therefore often inaccurate analytical models and accurate but time consuming FEAs [65].

Fig. 10 compares exemplary the measured and the acoustic modeling framework synthesized run-up spectrograms of a four-phase SRM. The eigenfrequency of the structural vibration response of mode 0 and mode 4 are clearly visible. The harmonics of the electric rotor frequency $f_{\mathrm{r}}$ can also be identified. The observed machine has a shape 0 excitation at multiples of $4 f_{\mathrm{r}}$ and a shape 4 excitation at all odd multiples of $f_{\mathrm{r}}$ [65]. Measurement and simulation show a high degree

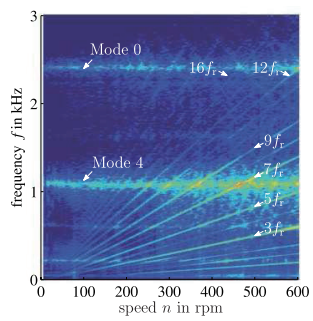

(a) Measured

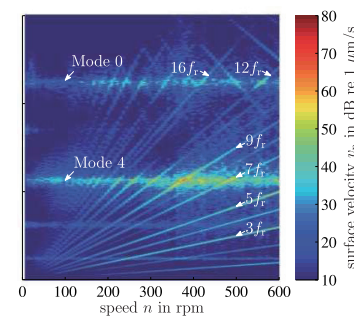

(b) Synthesized
Fig. 8. Acoustic modeling [68]. 
of accordance.

\section{Eccentricity}

The radial forces acting on the teeth surfaces of SRMs is known to cause vibrational and acoustic noise, as discussed before. However, in case of a rotor eccentricity, these radial forces are superposed by an additional unbalanced magnetic pull (UMP). Such an eccentricity can occur during fault operation or in normal operation caused by manufacturing tolerances.

Eccentricities are divided into static, dynamic and mixed eccentricities [72]. Thereby, a static eccentricity implies that the rotor's axis is not placed entirely in the center of the stator i.e. a shorter air-gap length on one side. With a dynamic or rotating eccentricity the rotor axis is not entirely in the center of the rotor, but is placed in the center of the stator. This creates a variable air-gap length which rotates with the rotor, i.e. is dependent on the rotor position and therefore also on machine speed [73].

To what extent eccentricity influences normal operation is discussed in [74]. The results show that the effect of possible eccentricity due to manufacturing tolerances should be considered during the drive design process by proper choice of rotor- and stator tooth width (tooth overlap during rotation). The air-gap length has a direct influence on the unbalanced magnetic pull. The smaller the air-gap length, the larger the effect which UMP has on the overall drive performance with respect to additional vibration.

Furthermore, different winding configuration can either worsen or mitigate the eccentricity effects on the drive. Connecting the machines phases in series causes much larger UMP compared to a machine with parallel connected phase windings. A parallel connection of opposite teeth windings causes a flux (current) balancing between the rotor teeth, resulting in a strongly reduced UMP acting on the bearings [73]. Therefore, with parallel windings the influence of manufacturing related asymmetries can be reduced.

The asymmetric force distribution due to an eccentricity causes an unbalanced force which excites secondary modes in addition to the initial vibration shapes which are discussed before. Investigations in [75], [76] show that the mode orders 1 and 2 are excited by UMP forces, regardless of the machine tooth configuration. In [76] a mathematical description for the excitation forces resulting from an eccentricity is derived. Thereby, eccentricity is described by a multiplication of two 2D Fourier series in space and time. From the mathematical representation it can be determined that a static eccentricity excites additional modes with the electrical harmonics, while in case of a rotating eccentricity mechanical-frequency side bands arise besides the initial electrical harmonics in the vibration spectrum of the machine.

Fig. 11 shows a simulated vibration spectrogram of an 18/12 automotive SRM without (Fig. 11(a)) and with a dynamic eccentricity (Fig. 11(b)). The additional frequency side bands from the dynamic eccentricity are well visible in Fig. 11(b).

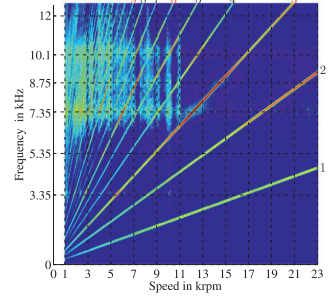

(a) Without eccentricity

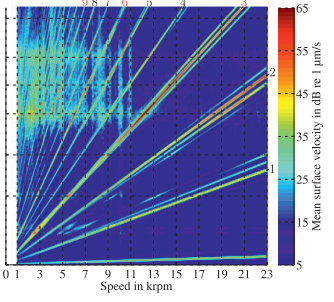

(b) With a dynamic eccentricity
Fig. 11. Simulated spectrograms with eccentricity from [76].

\section{Power Electronics}

\section{A. SRM Inverter}

The SRM inverter has to supply a positive voltage across the phase to magnetize this phase and a negative phase voltage for the demagnetization. A third state, which supplies zero voltage across the phase and, therefore, keeps the flux at a nearly constant level, is optional but important in terms of inverter efficiency and noise reduction. The commonly used inverter topology for SRMs is the asymmetric half bridge [77]. The switching states of the asymmetric half bridge and the resulting voltage loops are shown in Fig. 12. One asymmetric half bridge per phase is necessary to control each phase independently from the other phases. To reduce the number of semiconductors and/or wires between inverter and machine different topologies are discussed in literature [77], [78], e.g. the Miller topology and C-dump converter.

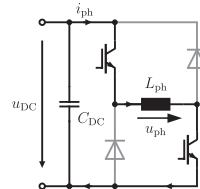

(a) Magnetization

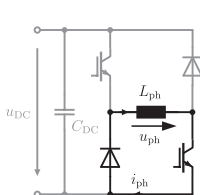

(b) Freewheeling

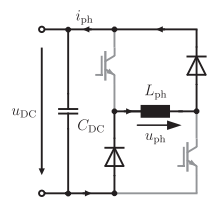

(c) Demagnetization
Fig. 12. Switching states of an asymmetric half bridge inverter.

\section{B. DC-Link Capacitor}

Switched reluctance machines need a comparatively large dc-link capacitor to smoothen the dc-link voltage due to the high amount of magnetization energy that oscillates between the dc-link and the machine [79]. A large dc-link capacitor increases the size, weight and price of the SRM inverter compared to inverters for conventional rotating field machines.

Recent publications recommend phase switching techniques to minimize the size of the dc-link capacitor [79]-[81]. These switching techniques aim at commutating the magnetization energy stored in one phase to the next active phase without buffering it in the dc-link capacitor. Additionally, in [81] a passive input filter is proposed to reduce the ripple on the source current. In [82] an active filter consisting of a bidirectional boost dc-dc converter is introduced (Fig. 13). The converter switches actively control the current between the 
dc-link and the voltage source.

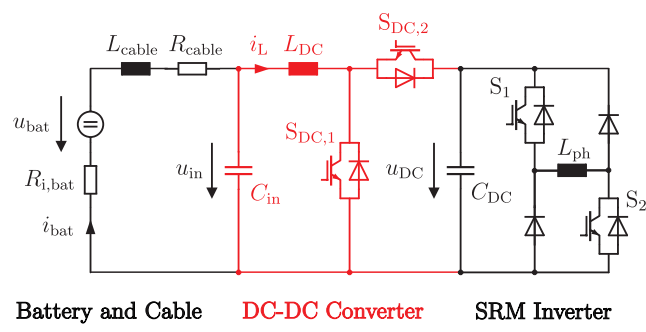

Fig. 13. Equivalent circuit of SRM with active filter [82].

\section{CONTROL}

For SRM control two main aspects are of interest: firstly, the position of the current pulse in each phase, which is controlled by the up to three parameter $\theta_{\text {on }}, \theta_{\text {free }}$ and $\theta_{\text {off }}$ Secondly, the shape of the current which is, at low speeds, controlled by a hysteresis or a PWM based switching scheme. The current shape strongly influences the instantaneous torque of the machine and is focus of many publications. At higher speeds, when the back-emf of the machine is in the range of the supply voltage, no switching is required to limit the phase current in single-pulse control (SPC). Many publications, such as [83], suggest ways to combine the control schemes for a smooth 4-quadrant operation of SRM in the full torque and speed operating range.

\section{A. Current Control}

The position dependent block-wise excitation of the sequential phases with a hysteresis current controller (HCC) is the most simple way to operate SRMs when smooth torque is not of interest (see Fig. 14). One potential to improve torque or acoustics is then to apply pre-calculated optimal current waveforms [84]. However a fast current acquisition and control device is required as for example proposed in [85]. If such a device is available, basically any desired current shape can be applied to the phase (see Fig. 15).

For efficiency reasons, above base speed most SRMs are operated in single-pulse control (SPC). In this operation mode, the current (and consequently torque) is controlled by the three switching angles mentioned before. With the position of the current pulses the behavior of the machine can be strongly influenced [8], [86], [87]. Output power control is mostly performed with a fixed $\theta_{\text {off }}$ (optimized for a specific design goal such as efficiency or acoustics) and by varying $\theta_{\text {on }}$ [87], [88].

In recent years, an additional focus has been laid on the potential to influence the system behavior by the third control parameter $\theta_{\text {free }}[89]$-[91]. Especially at low speed operation this optimization offers significant efficiency improvement for inverter and machine as it reduces the iron losses in the machine by reducing $\psi_{\text {peak }}$ [89], [91]. In [90] it is additionally found that even at nominal operation a short zero voltage period has a positive effect on the ac-losses caused by proximity effect in the machine windings. All op- timizations have in common, that torque ripple is generally increased, hence are only applicable were this is not a major requirement.

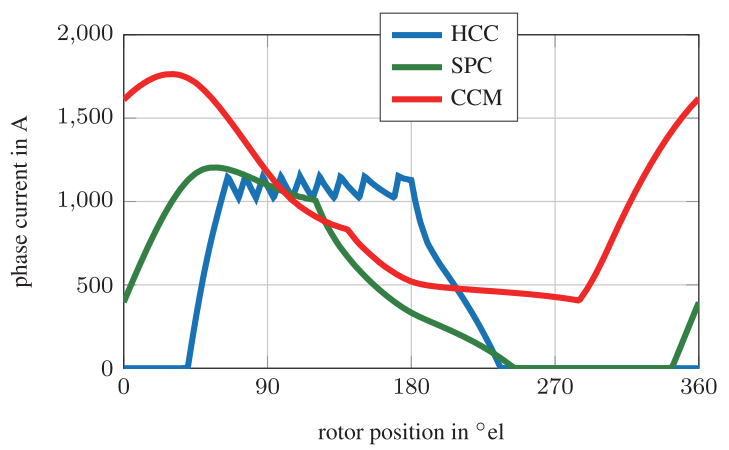

Fig. 14. Exemplary current shapes for different control modes.

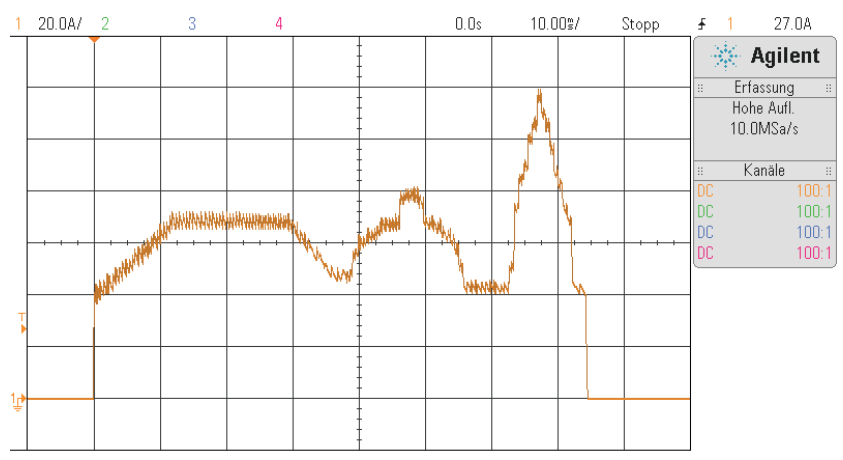

Fig. 15. Illustrating high dynamic current control in a 6-phase SRM. In this example the current waveform follows the outline of the cathedral in Aachen.

A significant torque boost at high speeds is offered by the so-called CCM [92] where the phase current does not reach zero any more. However, as it also increases the machine losses tremendously it is only applicable for short overload operation.

\section{B. Torque Control}

Pulsating torque is inherent to current controlled SRMs due to their doubly-salient structure and torque production principle. It is still considered as one of the main drawbacks of this drive technology. However, advances in power electronics and control hardware over the recent years have enabled the development of sophisticated control strategies that enable smooth torque output. The algorithms differ in their structure, implementation effort and operating range. The general goal of torque control schemes is to induce phase current waveforms such that the torque proportions of the single phases add up to constant torque output on the shaft. The different techniques can be roughly divided in several categories:

- indirect methods or current profiling methods

- direct torque control

Current profiling methods rely on offline or online computation of current profiles [94]-[96]. The profiles are derived by evaluation of experimental data or simulation and then 
stored as a mathematical function or a look-up table (LUT). Based on the stored profile a torque sharing function delivers torque minimizing control parameters for a cascaded current controller and initiates a suitable phase commutation.

Most of the current profiling algorithms suffer from a limited operating range and do not consider the machine dynamics at higher speed. More advanced torque sharing functions consider further important criteria besides torque ripple minimization. Since different current waveforms can deliver constant torque for the same operating point, additional requirements can be considered, e.g. minimized rms current, which is similar to maximum-torque-per-ampere (MTPA) techniques for rotating field machines, or minimized flux and accordingly minimized iron losses (maximum-torque-perflux- MTPF) [97], [98].

In contrast to indirect methods, direct instantaneous torque control (DITC) demonstrated in [99], [100] and predictive DITC [101], [102], a PWM version of DITC meant for microprocessor based hardware platforms, offer full flexibility and do not rely on predefined current profiles and commutation waveforms. Torque is estimated online, from a torque observer that uses the measured machine terminal quantities and a machine model (Fig. 17).

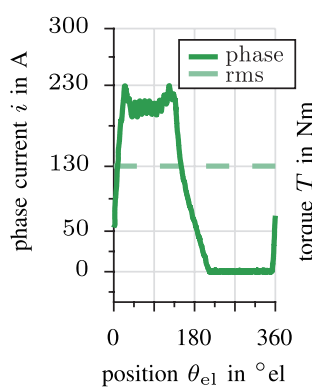

(a) Current

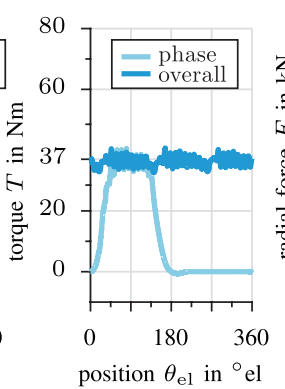

(b)Torque

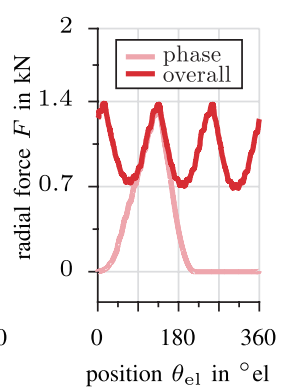

(c)Radial force
Fig. 16. Resulting trajectories applying DITC [93].

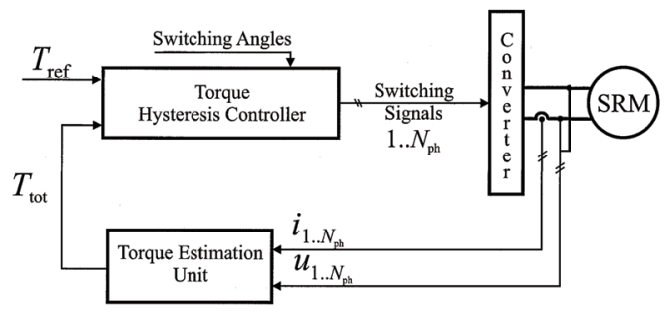

Fig. 17. Control diagram of DITC [100].

By controlling $\theta_{\text {on }}$ the current waveforms can be adapted to meet different secondary requirements like MTPA and MTPF optimization. The turn-on angle $\theta_{\text {on }}$ is varied depending on speed to ensure constant torque at higher speed. However, torque minimization techniques may reduce the system efficiency of reluctance drives [103].

Estimation of average torque, however, does not require pre-knowledge of the phase characteristics. This property of switched reluctance machines is used in [104] to develop direct average torque control (DATC) (Fig. 18). The estimated torque is compared to a reference value. The error is fed to a PIblock that adapts the control parameters of a cascaded current controller.

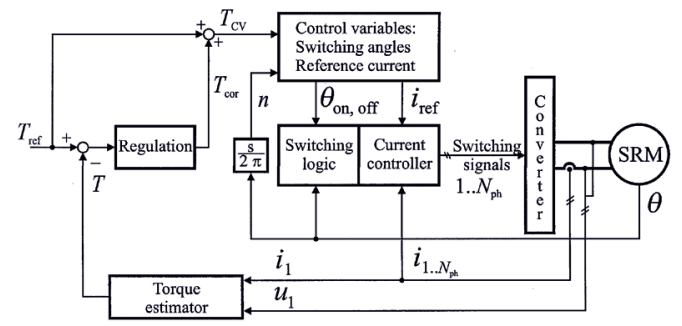

Fig. 18. Control diagram of DATC [104].

\section{Acoustic Control}

SRMs are prone to acoustic noise caused by stator vibrations due to high radial forces. Some research focuses on reducing actively the radial forces to overcome the noise issue [86], [87]. In [8] the influence of a switching angle dithering in singlepulse operation on the acoustics is investigated. However, recent publications [105]-[107] show that the vibration mode shape zero (M0), which is excited by a ripple on the overall radial force, is likely to be the predominant noise source in automotive-sized machines.

Therefore, recent approaches propose to keep the instantaneous overall radial force on a constant level. In [106]-[108] current profiles to fulfill this requirement are determined. Analog to DITC, in [7] Hofmann introduces the so-called direct instantaneous force control (DIFC), which calculates the required switching signals online to guarantee constant overall force. This approach can be implemented with PWM as well as hysteresis control [68].

Fig. 19 shows the resulting machine current, torque and radial force trajectories for a sample operating point applying DIFC. The brighter trajectories represent the phase torque and the phase radial force while the darker trajectories represent the overall torque and the overall radial force, respectively. The overall radial force is kept constant throughout the complete electrical period (Fig. 19(c)). A comparison of the synthesized run-up spectrogram for HCC and DIFC is shown in Fig. 20. Using HCC leads to increased surface velocity at the intersections of the eigenfrequency of mode shape zero $\left(f_{\mathrm{M} 0}\right)$ with the 3 rd and 6th harmonic of the electrical frequency (marked with white circles). DIFC is able to eliminate those peaks in the surface velocity.

DIFC and the indirect approach for constant overall radial force have in common, that both increase the ripple on the overall torque (Fig. 19(b)). Torque ripple has also an effect on the acoustic behavior as well as on drive-train oscillations. In [109], an approach is presented that defines a current profile to reduce the peak value of the produced radial force per pole and simultaneously tries to reduce the torque ripple during commutation. However, it only aims at decreasing the radialforce ripple rather than eliminate it completely.

Direct instantaneous force and torque control (DIT\&FC) 


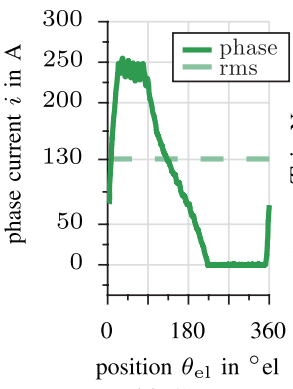

(a) Curren

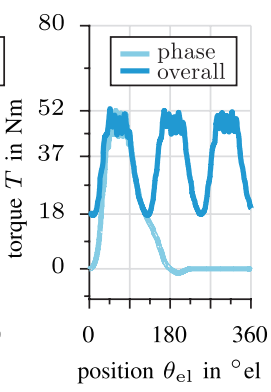

(b) Torque

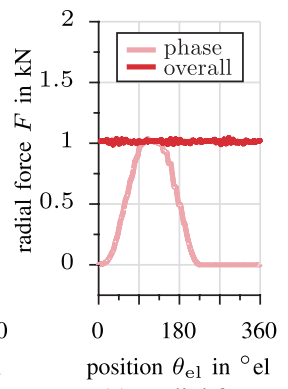

(c) Radial force
Fig. 19. Resulting trajectories when applying DIFC [93].

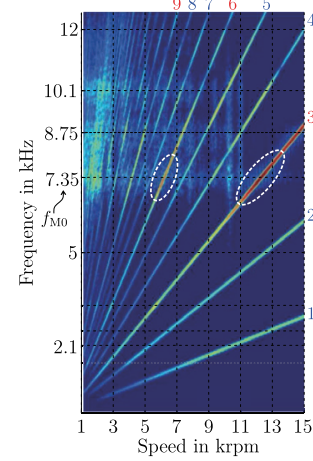

(a) $\mathrm{HCC}$

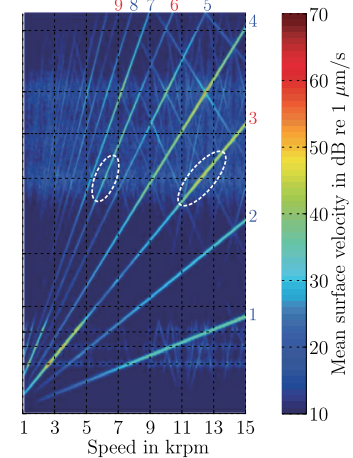

(b) DIFC
Fig. 20. Simulated run-up spectrograms of a three-phase 18/12 SRM [68].

unifies DITC and DIFC to simultaneously eliminate torque and force ripple [93]. An online search algorithm determines the appropriate phase flux-linkages and switching signals to fulfill both requirements: constant overall torque and constant overall radial force. Sample current, torque and radial force trajectories are shown in Fig. 21. However, the twofold control objective inherently reduces the drive efficiency due to an increased rms current [93].

All previously presented approaches have the drawback that they depend on predetermined machine characteristics or an offline post-processed parameter optimization. The proposed control optimization in [110] uses a vibration sensor feedback in the control loop to improve the acoustic behavior of the machine online during operation (Fig. 22(a)). Investigations have shown that the modulation of harmonic content on a control reference signal affects the acoustic be-

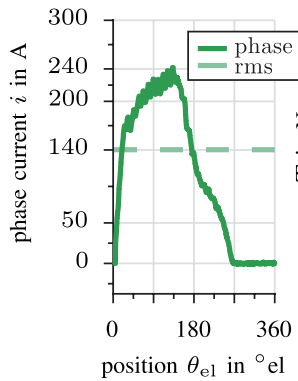

(a) Current

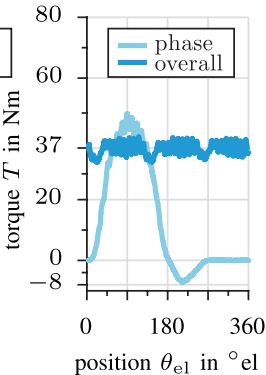

(b) Torque

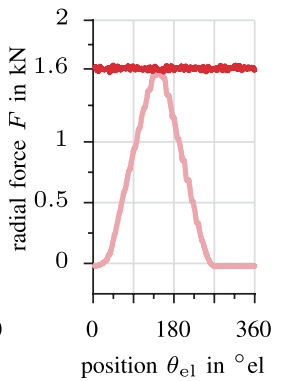

(c) Radial force
Fig. 21. Resulting trajectories when applying DIT\&FC [93]. havior of the SRM. An online search algorithm determines the optimal modulation parameter. Fig. 22(b) shows a proof of concept. The increased surface velocity at the mode-zero eigenfrequency $(7.2 \mathrm{kHz})$ is totally eliminated while the overall torque and overall radial force trajectories are barely affected by the modulation. The approach is independent of the used control method and can also be applied with, e.g. DITC.

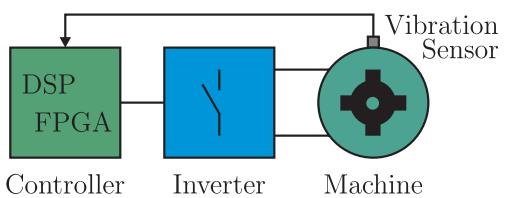

(a) Feedback loop

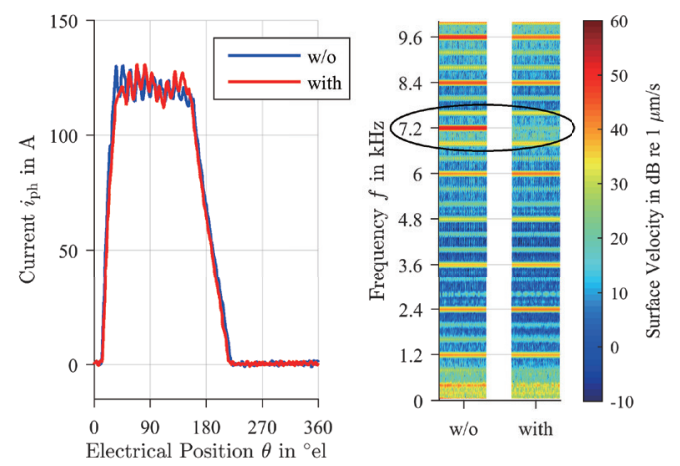

(b) Current control with and without vibration sensor feedback

Fig. 22. Vibration sensor feedback to the controller [110].

\section{Self-Sensing of SRMs}

A number of methods for position sensorless operation of SRMs have been studied in literature. Most techniques take advantage of the doubly salient geometry of SRMs which results in strongly position dependent flux characteristic. The flux characteristic (though nonlinear) is a defined function between phase current, flux linkage and rotor position (Fig. 23). The knowledge of two quantities is sufficient to estimate the third, provided that the characteristic is available. Methods for deriving the motor characteristics are discussed in Chapter IV.

Various approaches to extract the rotor position from the phase characteristic have been presented in literature. Comprehensive studies giving an overview over sensorless techniques are presented in [111]-[113]. The main classification

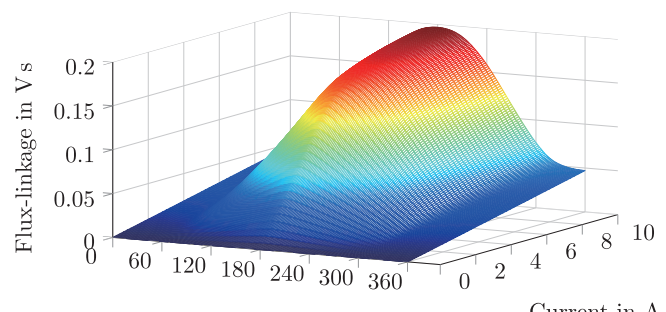

Rotor position in ${ }^{\circ} \mathrm{el}$

Fig. 23. Typical phase characteristic of a switched reluctance motor. 
criteria can be listed as follows:

- Phase state: active or passive phase methods depending on whether the phase is also used for torque production or not

- Hardware effort: depending on how much computational power is necessary and whether additional sensing hardware is used

- Speed range: defining the range in which the algorithms are applicable

- Periodicity of measurement: Continuous detection of rotor position or detection at certain defined rotor position

- Signal injection: direct methods, that apply signal injection to detect the rotor position and indirect methods that make use of the terminal quantities only.

A commonly applied active phase approach is the fluxlinkage method [114]. It does not require additional hardware and estimates the rotor position from the measured phase current and applied flux linkage. However, a machine model must be available, usually derived from finite element simulations or static measurements and stored as a LUT. Since flux linkage is derived by integration of the phase votlage the algorithm is not suitable for near zero speed. Further modifications and improvements of the flux-linkage method are suggested in [115], [116]. Another approach to improve the position detection is to employ additional filters and self-calibration routines [117]. Other common active phase methods employ current monitoring, current gradient measurements and various model observer [118], [119]. One of the first approaches for stepper application of SRMs without position sensor is presented in [120].

Sensorless operation over the complete speed range can be achieved by combining the flux-linkage method with signal injection methods in the low speed and low torque area. Current signals with small magnitude, typically a fraction of the rated value [118], are injected in one of the idle phases to estimate the phase inductance and derive the rotor position. However, signal injection methods can lead to undesired torque production in the machine and worsened acoustic behavior.

\section{E. Control Hardware}

Switched reluctance machines cannot be fed directly from the power grid or be applied as generators without dedicated power electronic converters and active switching strategies implemented in digital or analog electronic circuits. When SRDs were introduced, digital computation devices were not available or not powerful enough to accommodate the sophisticated control strategies, that minimized torque ripple or acoustic noise. This is one of main reasons why switched reluctance drives have been disregarded for a long time.

Nowadays state-of-the-art control platforms for SRMs are based on digital signal processors (DSPs), similar to rotating field machines. They allow fast computation, storage of machine characteristics and tracking of terminal quantities. Lately field programmable gate arrays (FPGAs) are getting attractive as a control hardware for SRDs due to their oversampling capability and high parallelization grade. The rapid development and the steadily decreasing cost of FPGAs makes them a viable option to DSPs. In mass production FPGAs can be replaced by custom chips called ASICs (application-specific integrated circuit) to reduce the hardware cost. An example for a commercially available chip enabling sensorless control of SRMs is given in [121]. Modern chips containing both DSP and FPGA blocks gain attention for motor control due to their flexibility. Timely critical control tasks can be assigned to the FPGA while the microprocessor takes over more complex high level control (Fig. 24).

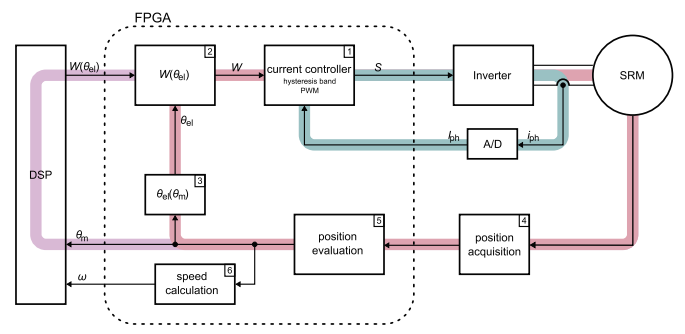

Fig. 24. Controller structure in a combined DSP-FPGA platform [85]

Depending on the target hardware different implementation techniques need to be applied. DSPs execute their program sequentially and usually have fixed interrupts. Depending on the complexity of the control algorithm and the processor performance control of electrical frequencies of up to several $\mathrm{kHz}$ are possible. Due to the limited signal tracking capability compared to FPGAs, DSPs are usually the target hardware for PWM based algorithms.

Hysteresis based algorithms however, where the switching action directly depends on values of the terminal quantities, are generally more suited for FPGA target hardware. Conventional hysteresis current control as well as torque and force controllers like DITC, hysteresis based DIFC [20] and various current profiling techniques benefit from an FPGA implementation. A fully FPGA-based current controller including both PWM and hysteresis band modulation was demonstrated in [85]. The FPGA implementation of state of the art predictive DITC is discussed in [122]. The advantages of FPGAs can be exploited for high-grade position detection techniques as in [117].

In particular the choice of hardware depends mainly on the system dynamics. Especially highly dynamic SRMs and highspeed drives require fast signal tracking. Devices operating with fixed switching frequency as most DSPs can switch only at discrete time steps. At high speed, this leads to a turnon angle uncertainty, i.e. the exact turn on angle cannot be met and phase commutation takes place earlier or later than desired (Fig. 25). This effect can lead to power oscillations and consequently to a limitation of the operating range. 

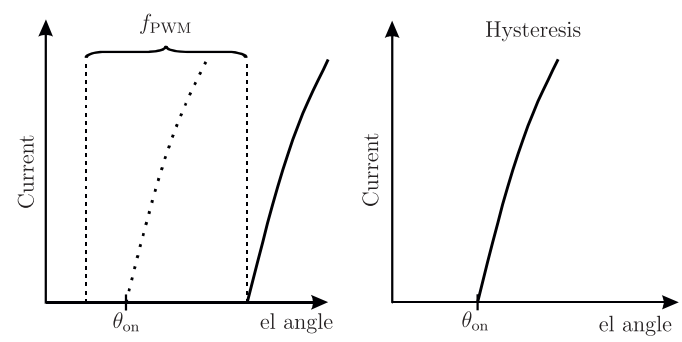

Fig. 25. Turn-on uncertainty of PWM algorithms at high speed.

\section{SRM IN APPLICATION}

Today, SRMs are found in a number of niche products throughout the industry, some of which are discussed in this section. Furthermore, the section highlights the current research landscape dealing with SRMs followed by an outlook on open research topics to be tackled in the near future.

\section{A. Available Solutions}

For household applications the best-known companies using switched reluctance machines are Vorwerk and Dyson. The first and second generations of Vorwerk's Thermomix use a 500W SRM with a speed range of $40 \mathrm{rpm}$ up to 10700 rpm [123]. Furthermore, the Kobold 140/150 vacuum cleaner by Vorwerk has a 900W SRM with speeds of up to 60 krpm [124]. A further industrial vacuum cleaner with SRMs is constructed by Ametek [125]. Even higher speeds and therefore an even higher power density is used by Dyson in their vacuum cleaners and hand dryers. The hand dryers use a one pole-pair SRM with speed up to $90 \mathrm{krpm}$ and $1600 \mathrm{~W}$ nominal power [126].

Other high-speed applications such as weaving machines or centrifuges use SRMs as well. The company Picanol uses reluctance machines from the company Nidec SR-Drives for weaving machines [127], while the company Beckman Coulter exploits the benefit of low rotor inertia and the resulting fast acceleration of SRMs in their centrifuges. The centrifuges are operated between $10 \mathrm{krpm}$ and $30 \mathrm{krpm}$ [128]. The airconditioning compressor unit of German ICE3 high-speed passenger train is powered by an SRD with up to $40 \mathrm{~kW}$ at $23 \mathrm{krpm}$ also from Nidec SR-Drives [129]. A further application benefiting from the low rotor inertia and resulting small time constants are electric compressors, e.g. electric turbo chargers. The company Valeo proposes a near future entry into the automotive market. The proposed SRM, on $12 \mathrm{~V}$ and $48 \mathrm{~V}$ basis is designed to accelerate up to 70 krpm within $350 \mathrm{~ms}$ and $200 \mathrm{~ms}$ respectively [130], [131].

Another application designated for SRM are power tools. The company Hilti uses a special form of one phase SRM with magnets in the stator for demolition hammers and diamond grinders up to $1800 \mathrm{~W}$ and $22 \mathrm{krpm}$ e.g. TE $1000-$ AVR or DG150 [132]. In these applications torque ripple and vibration (acoustic noise) are not an issue, highlighting the SRM's advantages in respect to cost and robustness. Robustness and low maintenance is also a crucial advantage in the highpower application of wheel-loaders. LeTourneau (since 2002) and more recently John Deere (since 2013) employ Nidec SR-Drives technology in one of their biggest hybrid electric systems [133].

\section{B. Research and Development}

Giving a complete overview on the SRM application research landscape is quite impossible. However, some applications have received increased attention from researchers all over the world. One topic are high-speed turbo machines and generators due to their robust rotor structure. A wide overview can be found in [134]. Especially aircraft starter-generators and fuel pumps in the range of several ten $\mathrm{kW}$ have already been investigated by many working groups [135]. Another focus is the automotive industry searching for magnet-free traction drive alternatives for the roll out of millions of electric cars [136]. The cost advantage of SRDs also plays an important role in range extender (and backup power) systems presented in [137].

\section{Conclusions}

Over the past decades, all major issues of SRDs have been addressed. Hence, SRDs are ready to be implemented in applications, if the requirements necessitate its main advantages. Compared to common rotating field machines, these advantages are large speed-range, the possibility for a high torque overload, high torque dynamics, a simple and robust mechanical construction (e.g. one phase machines), lowcost production and the exclusion of rare-earth materials. In lowspeed applications, with regard to the SRD's acoustic behavior, power density and efficiency, the SRM cannot outperform rotation field machines, despite the advances in control and design that are shown within this paper.

\section{REFERENCE}

[1] W. H. Taylor, "Improvements in obtaining power by means of electro-magnetism," 8255.

[2] P. J. Lawrenson, J. M. Stephenson, P. T. Blenkinsop, J. Corda, and N. N. Fulton, "Variable-speed switched reluctance motors," in IEE Proceedings B - Electric Power Applications 127.4, 1980, pp. 253265.

[3] B. J. Chalmers, and L. Musaba, "Design and field-weakening performance of a synchronous reluctance motor with axially laminated rotor," in IEEE Transactions on Industry Applications 34.5, pp. 10351041, Sept.1998.

[4] H. Lendenmann, R. Moghaddam, A. Tammi, and L. Thand, "Motoring Ahead," in ABB review 1, 2011, pp. 56-61.

[5] Traction Developments, Electric \& Hybrid Vehicle Technology International, 2011.

[6] D. Cameron, J. H. Lang, and S. Umans, "The origin and reduction of acoustic noise in doubly salient variable-reluctance motors," in IEEE Transactions on Industry Applications 28.6, pp. 1250-1255, 1992.

[7] A. Hofmann, A. Al-Dajani, M. Boesing, and R. W. De Doncker, "Direct instantaneous force control: A method to eliminate mode-0borne noise in switched reluctance machines," in IEEE International Electric Machines and Drives Conference (IEMDC), May 2013, pp. 1009-1016.

[8] D. Scharfenstein, B. Burkhart, and R. W. De Doncker, "Influence of an FPGA-based switching angle dithering on acoustics in single- 
pulse controlled switched reluctance machines," in IEEE 11th International Conference on Power Electronics and Drive Systems, 2015, pp. 754-761.

[9] C. M. Stephens, "Fault detection and management system for faulttolerant switched reluctance motor drives, " in IEEE Transactions on Industry Applications 27.6, pp. 1098-1102, 1991.

[10] R. Krishnan, R. Arumugan, and J. F. Lindsay, "Design procedure for switched-reluctance motors," in IEEE Transactions on Industry Applications 24.3, pp. 456-461, 1988.

[11] T. J. E. Miller, Switched Reluctance Motors and Their Control, vol. 31, Monographs in Electrical and Electronic Engineering, Clarendon Press, 1993.

[12] J. Hendershot, and T. J. E. Miller, Design of brushless permanent magnet motors, vol. 37, Monographs in Electrical and Electronic Engineering, Magna Physics Pub, 1994.

[13] T. J. E. Miller, "Optimal design of switched reluctance motors," in IEEE Transactions on Industrial Electronics 49.1, pp. 15-27, 2002.

[14] SPEED Consortium. PC-SRD. 2008.

[15] N. H. Fuengwarodsakul, J. O. Fiedler, S. E. Bauer, and R. W. De Doncker, "New methodology in sizing and predesign of switched reluctance machines using normalized flux-linkage diagram," in European Conference on Power Electronics and Applications. vol. 4, 2005, pp. 2704-2711.

[16] H. J. Brauer, B. Burkhart, and R. W. De Doncker. "Comprehensive electromagnetic design procedure for switched reluctance machines," in 6th IET International Conference on Power Electronics, Machines and Drives (PEMD 2012), 2012, pp. 1-6.

[17] H. J. Brauer, Schnelldrehender geschalteter Reluktanzantrieb mit extremem Längendurchmesserverhältnis: Zugl.: Aachen, Techn. Hochsch., Diss., 2013, vol. 68, Aachener Beiträge des ISEA, Aachen: Shaker, 2013.

[18] B. Burkhart, A. Mittelstedt, and R. W. De Doncker, "Solution space based pre-design approach to compare and select configurations of switched reluctance machines, " in 8th IET International Conference on Power Electronics, Machines and Drives (PEMD), 2016, pp. 1-6.

[19] W. Uddin, T. Husain, Y. Sozer, and I. Husain, "Design methodology of a switched reluctance machine for off-road vehicle applications," in IEEE Transactions on Industry Applications 52.3, pp. 2138-2147, 2016.

[20] A. Hofmann, F. Qi, and R. W. De Doncker, "Developing the concept for an automotive high-speed SRM drive with focus on acoustics," in 7th IET International Conference on Power Electronics, Machines and Drives (PEMD), 2014, pp. 1-5.

[21] A. Chiba, Y. Takano, M. Takeno, T. Imakawa, N. Hoshi, M. Takemoto, and S. Ogasawara, "Torque density and efficiency improvements of a switched reluctance motor without rare-earth material for hybrid vehicles". In: IEEE Transactions on Industry Applications 47.3, pp. 1240-1246, 2011.

[22] C. E. Carstensen, Eddy currents in windings of switched reluctance machines: Zugl.: Aachen, Techn. Hochsch., Diss., 2007, vol. 48, Aachener Beiträge des ISEA, Aachen: Shaker, 2008.

[23] J. O. Fiedler, "Design of Low-Noise Switched Reluctance Drives," Dissertation, Aachen: RWTH Aachen University, 2006.

[24] B. C. Mecrow, J. W. Finch, E. A. E. Kharashi, and A. G. Jack, "Switched reluctance motors with segmental rotors," in IEE Proceedings Electric Power Applications 149.4, 2002, pp. 245-254.

[25] B. C. Mecrow, E. A. E. Kharashi, J. W. Finch, and A. G. Jack, "Preliminary performance evaluation of switched reluctance motors with segmental rotors," in IEEE Transactions on Energy Conversion 19.4, pp. 679-686, 2004.

[26] M. Abbasian, M. Moallem, and B. Fahimi, "Double-stator switched reluctance machines (DSSRM): Fundamentals and magnetic force analysis," in IEEE Transactions on Energy Conversion 25.3, pp. 589-597, 2010.

[27] A. Jain, and N. Mohan, "Dynamic modeling, experimental characterization, and verification for SRM operation with simultaneous two-phase excitation," in IEEE Transactions on Industrial Electronics 53.4, pp. 1238-1249, Jun. 2006.

[28] N. H. Fuengwarodsakul, R. Inderka, and R. De Doncker, "Simulation Model of a Switched Reluctance Drive in 42 V Application,". in IECON '03, The 29th Annual Conference of the IEEE Industrial Electronics Society, vol. 3. Nov. 2003, 2871-2876.

[29] W. Ding, D. Liang, and H. Sui, "Dynamic modeling and performance prediction for dual-channel switched reluctance machine considering mutual coupling," in IEEE Transactions on Magnetics 46.9, pp. 3652-3663, Sept. 2010.

[30] T. J. E. Miller, and M. McGilp, "Nonlinear theory of the switched reluctance motor for rapid computer-aided design," in IEE Proceedings B - Electric Power Applications 137.6, Nov. 1990, pp. 337-347.

[31] T. J. E. Miller, "Faults and unbalance forces in the switched reluctance machine," in Industry Applications, IEEE Transactions on 31.2, pp. 319-328, Mar. 1995.

[32] T. J. E. Miller, M. Glinka, M. McGilp, C. Cossar, G. Gallegos-Lopez, D. Ionel, and M. Olaru, "Ultra-fast model of the switched reluctance motor," in Conference Record of 1998 IEEE Industry Applications Conference. Thirty-Third IAS Annual Meeting (Cat. No.98CH36242), vol. 1, Oct. 1998, 319-326.

[33] A. Radun, "Analytical calculation of the switched reluctance motor's unaligned inductance," in IEEE Transactions on Magnetics 35.6, pp. 4473-4481, Nov. 1999.

[34] J. C. Moreira, and T. A. Lipo, "Simulation of a four phase switched reluctance motor including the effects of mutual coupling," in Electric Machines \& Power Systems 16.4, 1989, pp. 281-299.

[35] J. Kokernak, and D. Torrey, "Magnetic circuit model for the mutually coupled switched-reluctance machine," in IEEE Transactions on Magnetics 36.2, pp. 500-507, Mar. 2000.

[36] M. Hennen, Switched reluctance direct drive with integrated distributed inverter: Zugl.: Aachen, Techn. Hochsch., Diss., 2011, vol. 60, Aachener Beiträge des ISEA, Aachen: Shaker, 2012.

[37] C. Weiss, M. Huebner, M. Hennen, and R. De Doncker, "Switched Reluctance Machine Model Considering Asymmetries and Enabling Dynamic Fault Simulation," in IEEE International Electric Machines and Drives Conference. 2013.

[38] H. W. Derbas, J. M. Williams, A. C. Koenig, and S. D. Pekarek, "A comparison of nodal- and mesh-based magnetic equivalent circuit models," in IEEE Transactions on Energy Conversion 24.2, pp. 388396, Jun. 2009.

[39] M. Schenk, A. Hofmann, and R. W. De Doncker, "Automated copper loss analysis for switched reluctance machines," in EPE Journal 26.1, pp. 2-10, 2016.

[40] K. Nakamura, S. Fujio, and O. Ichinokura, "A method for calculating iron loss of an SR motor based on reluctance network analysis and comparison of symmetric and asymmetric excitation," in IEEE Transactions on Magnetics 42.10, pp. 3440-3442, Oct. 2006.

[41] D. van Treek, P. Matuschek, H. J. Brauer, T. Schoenen, and R. W. De Doncker, "An automatic identification of phase inductance for operation of switched reluctance machines without position sensor," in 2009 IEEE International Electric Machines and Drives Conference. 2009, pp. 1005-1009.

[42] F. Fleming, "Real-time switched reluctance machine emulation via magnetic equivalent circuit", Paper 8987, Florida State University, 2014.

[43] F. E. Fleming, and C. S. Edrington. "Real-time emulation of switched reluctance machines via magnetic equivalent circuits," in IEEE Transactions on Industrial Electronics 63.6, pp. 3366-3376, Jun. 2016.

[44] M. Schenk, "Simulative untersuchung der wicklungsverluste in geschalteten reluktanzmaschinen," Dissertation, RWTH Aachen and Shaker Verlag GmbH, 2015.

[45] A. Krings. "Iron losses in electrical machines - influence of material properties, manufacturing processes and inverter operation". $\mathrm{PhD}$ thesis, KTH Royal Institute of Technology, 2014.

[46] D. Eggers, S. Steentjes, and K. Hameyer, "Advanced iron-loss estimation for nonlinear material behavior," in IEEE Transactions on Magnetics 48.11, pp. 3021-3024, Nov. 2012.

[47] A. Klein-Hessling, B. Burkhart, and R. W. De Doncker, "Iron loss redistribution in switched reluctance machines using bidirectional phase currents," in 8th IET International Conference on Power Electronics, Machines and Drives (PEMD). Apr. 2016, pp. 1-6.

[48] C. P. Steinmetz, "On the Law of Hysteresis," in Transactions of the American Institute of Electrical Engineers IX.1, pp. 1-64, Jan. 1892. 
[49] D. C. Jiles, and D. L. Atherton, "Theory of ferromagnetic hysteresis," in Journal of Magnetism and Magnetic Materials 62.1, pp. 4860, 1986.

[50] J. Reinert, A. Brockmeyer, and R. W. A. A. De Doncker, "Calculation of losses in ferro- and ferrimagnetic materials based on the modified Steinmetz equation," in IEEE Transactions on Industry Applications 37.4, pp. 1055-1061, Jul. 2001.

[51] K. Venkatachalam, C. R. Sullivan, T. Abdallah, and H. Tacca, “Accurate prediction of ferrite core loss with nonsinusoidal waveforms using only Steinmetz parameters," in Proceedings of IEEE Workshop on Computers in Power Electronics. Jun. 2002, pp. 36-41.

[52] P. N. Materu and R. Krishnan, "Estimation of switched reluctance motor losses," in IEEE Transactions on Industry Applications 28.3, pp. 668-679, 1992.

[53] J. Vrancik, Prediction of Windage Power Loss in Alternators, 1968.

[54] K. Kiyota, T. Kakishima, and A. Chiba, "Estimation and comparison of the windage loss of a $60 \mathrm{~kW}$ Switched Reluctance Motor for hybrid electric vehicles," in International Power Electronics Conference (IPEC-Hiroshima - ECCE-ASIA), 2014, pp. 3513-3518.

[55] K. Kiyota, T. Kakishima, A. Chiba, and M. A. Rahman, "Cylindrical rotor design for acoustic noise and windage loss reduction in switched reluctance motor for HEV applications," in IEEE Transactions on Industry Applications 52.1, pp. 154-162, 2016.

[56] F. Qi, I. Ralev, A. Klein-Hessling, and R. W. De Doncker, "Online temperature estimation of an automotive switched reluctance motor using space-resolved lumped parameter network," in 19th International Conference on Electrical Machines and Systems (ICEMS). Nov. 2016, pp. 1-6.

[57] P. H. Mellor, D. Roberts, and D. R. Turner, "Lumped parameter thermal model for electrical machines of TEFC design," in IEE Proceedings B - Electric Power Applications 138.5, Sept. 1991, pp. 205218.

[58] S. Inamura, T. Sakai, and K. Sawa, "A temperature rise analysis of switched reluctance motor due to the core and copper loss by FEM," in IEEE Transactions on Magnetics 39.3, pp. 1554-1557, May 2003.

[59] D. Staton, A. Boglietti, and A. Cavagnino, "Solving the more difficult aspects of electric motor thermal analysis in small and medium size industrial induction motors," in IEEE Transactions on Energy Conversion 20.3, pp. 620-628, 2005.

[60] F. Qi, A. Stippich, M. Guettler, M. Neubert, and R. W. De Doncker, "Methodical considerations for setting up space-resolved lumpedparameter thermal models for electrical machines," in 17th International Conference on Electrical Machines and Systems (ICEMS). Oct. 2014, pp. 651-657.

[61] G. G. Guemo, P. Chantrenne, and J. Jac, "Application of classic and T lumped parameter thermal models for Permanent Magnet Synchronous Machines," in IEEE International Electric Machines and Drives Conference (IEMDC). May 2013, pp. 809-815.

[62] N. Simpson, R. Wrobel, and P. H. Mellor, "An accurate mesh-based equivalent circuit approach to thermal modeling," in IEEE Transactions on Magnetics 50.2, pp. 269-272, Feb. 2014.

[63] F. Qi, I. Ralev, A. Stippich, and R. W. De Doncker, "Model predictive overload control of an automotive switched reluctance motor for frequent rapid accelerations," in 19th International Conference on Electrical Machines and Systems (ICEMS). Nov. 2016, pp. 1-6.

[64] P. L. Timar, A. F. J. Kiss, A. Miklos, and S. Yang, Noise and Vibration of Electrical Machines. P. L. Timar, Ed. Elsevier, 1989.

[65] M. Bösing, Acoustic modeling of electrical drives: Noise and vibration synthesis based on force response superposition: Zugl.: Aachen, Techn. Hochsch., Diss., 2013, vol. 71, Aachener Beiträge des ISEA, Aachen: Shaker, 2014.

[66] J. O. Fiedler, K. A. Kasper, and R. W. De Doncker, "Acoustic noise in switched reluctance drives: an aerodynamic problem?" in IEEE International Conference on Electric Machines and Drives (IEMDC). May 2005, pp. 1275-1280.

[67] H. Jordan, Geraeuscharme Elektromotoren - Laermbildung und Laermbeseitigung bei Elektromotoren. Essen. W. Giradet, Ed. 1950

[68] A. Hofmann, Direct Instantaneous Force Control: Key to Low-Noise Switched Reluctance Traction Drives. 1, Auflage, vol. 83, Aachener Beiträge des ISEA, Aachen: Shaker, 2016.

[69] J. O. Fiedler, K. A. Kasper, and R. W. De Doncker, "Calculation of the acoustic noise spectrum of SRM using modal superposition," in IEEE Transactions on Industrial Electronics 57.9, pp. 2939-2945, Sept. 2010.

[70] A. Hubert and G. Friedrich, "Influence of power converter on induction motor acoustic noise: interaction between control strategy and mechanical structure," in IEE Proceedings - Electric Power Applications 149.2, pp. 93-100, Mar. 2002

[71] M. Boesing, A. Hofmann, and R. De Doncker, "Universal acoustic modelling framework for electrical drives," in IET Power Electronics 8.5, pp. 693-699, 2015.

[72] H. Torkaman, E. Afjei, and P. Yadegari, "Static, dynamic, and mixed eccentricity faults diagnosis in switched reluctance motors using transient finite element method and experiments,". in IEEE Transactions on Magnetics 48.8, pp. 2254-2264, Aug. 2012.

[73] A. Hofmann, F. Qi, C. Weiss, and R. De Doncker, "Efficiently modeling rotor eccentricity in switched reluctance machines," in 16th European Conference on Power Electronics and Applications, 2014.

[74] C. Weiss, F. Qi, A. Hofmann, and R. De Doncker, "Analysis and Modelling of Rotor Eccentricity for Switched Reluctance Machines," in 7th IET International Conference on Power Electronics, Machines and Drives, 2014

[75] A. Hofmann, F. Qi, C. P. Weiss, and R. De Doncker, "The acoustic impact of rotor eccentricity in switched reluctance machines," in 16th European Conference on Power Electronics and Applications. Aug. 2014, pp. 1-10.

[76] A. Hofmann, F. Qi, C. P. Weiss, T. Kojima, and R. De Doncker, "The acoustic impact of rotor eccentricity in switched reluctance machines," in EPE Journal 26.2, pp. 47-57, 2016.

[77] M. Barnes, and C. Pollock, "Power electronic converters for switched reluctance drives," in IEEE Transactions on Power Electronics 13.6, pp. 1100-1111, Nov. 1998.

[78] S. Vukosavic, and V. R. Stefanovic, "SRM inverter topologies: a comparative evaluation," in IEEE Transactions on Industry Applications 27.6, pp. 1034-1047, Nov. 1991.

[79] C. R. Neuhaus, N. H. Fuengwarodsakul, and R. W. De Doncker, "Control scheme for switched reluctance drives with minimized DClink capacitance," in IEEE Transactions on Power Electronics 23.5, pp. 2557-2564, Sept. 2008

[80] C. R. Neuhaus, Schaltstrategien für geschaltete Reluktanzantriebe mit kleinem Zwischenkreis: Zugl.: Aachen, Techn. Hochsch., Diss. 2011, vol. 64, Aachener Beiträge des ISEA, Aachen: Shaker, 2012.

[81] W. Suppharangsan, and J. Wang, "Switching technique for minimisation of DC-link capacitance in switched reluctance machine drives," in IET Electrical Systems in Transportation 5.4, 2015, pp. 185-193.

[82] A. Klein-Hessling, B. Burkhart, and R. W. De Doncker, "Active source current filtering to minimize the DC-link capacitor in switched reluctance drives," in 2nd IEEE Annual Southern Power Electronics Conference (SPEC), Dec. 2016, pp. 1-7.

[83] I. Kioskeridis, and C. Mademlis, "A unified approach for four-quadrant optimal controlled switched reluctance machine drives with smooth transition Between Control Operations," in IEEE Transactions on Power Electronics 24.1, pp. 301-306, 2009.

[84] H. C. Lovatt, and J. M. Stephenson, "Computer-optimised smoothtorque current waveforms for switched-reluctance motors," in IEE Proceedings Electric Power Applications 144.5, 1997, pp. 310-316.

[85] J. Gottschlich, B. Burkhart, C. Coenen, and R. W. De Doncker, "Fully digital FPGA-based current controller for switched reluctance machines," in IEEE International Symposium on Sensorless Control for Electrical Drives and Predictive Control of Electrical Drives and Power Electronics (SLED/PRECEDE), 2013, pp. 1-7.

[86] K. A. Kasper, Analysis and control of the acoustic behavior of switched reluctance drives: Zugl.: Aachen, Techn. Hochsch., Diss., 2010, vol. 57. Aachener Beiträge des ISEA, Aachen: Shaker, 2011.

[87] A. Klein-Hessling, B. Burkhart, D. Scharfenstein, and R. W. De Doncker, "The effect of excitation angles in single-pulse controlled switched reluctance machines on acoustics and efficiency," in 17th International Conference on Electrical Machines and Systems (ICEMS), 2014, pp. 2661-2666.

[88] Y. Sozer, and D. A. Torrey, "Closed loop control of excitation parameters for high speed switched-reluctance generators," in IEEE Transactions on Power Electronics 19.2, pp. 355-362, 2004. 
[89] T. Kojima, and R. W. De Doncker, "Impact of zero-volt loop control on efficiency of switched reluctance motors," in IEEE Transactions on Industry Applications PP.99 (2017), p. 1.

[90] B. Burkhart, A. Klein-Hessling, S. A. Hafeez, and R. W. De Doncker, "Influence of freewheeling on single pulse operation of a switched reluctance generator," in 19th International Conference on Electrical Machines and Systems (ICEMS), 2016.

[91] W. U. Nuwantha Fernando, and M. Barnes., "Electromagnetic energy conversion efficiency enhancement of switched reluctance motors with zero-voltage loop current commutation," in IEEE Transactions on Energy Conversion 28.3, pp. 482-492, 2013.

[92] H. Hannoun, M. Hilairet, and C. Marchand, "Experimental validation of a switched reluctance machine operating in continuous-conduction mode," in IEEE Transactions on Vehicular Technology 60.4, pp. 1453-1460, 2011

[93] A. Klein-Hessling, A. Hofmann, and R. W. De Doncker, "Direct instantaneous torque and force control: A control approach for switched reluctance machines," in IET Electric Power Applications, 2016.

[94] D. S. Schramm, B. W. Williams, and T. C. Green, "Torque ripple reduction of switched reluctance motors by phase current optimal profiling," in Power Electronics Specialists Conference, 1992. PESC '92 Record., 23rd Annual IEEE, 1992, pp. 857-860.

[95] R. S. Wallace, and D. G. Taylor, "A balanced commutator for switched reluctance motors to reduce torque ripple," in IEEE Transactions on Power Electronics 7.4, pp. 617-626, 1992.

[96] I. Husain, and M. Ehsani, "Torque ripple minimization in switched reluctance motor drives by PWM current control," in IEEE Transactions on Power Electronics 11.1, pp. 83-88, 1996.

[97] P. C. Kjaer, J. J. Gribble, and T. J. E. Miller, "High-grade control of switched reluctance machines," in IEEE Transactions on Industry Applications 33.6, pp. 1585-1593, 1997.

[98] V. P. Vujicic, "Minimization of torque ripple and copper losses in switched reluctance drive," in IEEE Transactions on Power Electronics 27.1, pp. 388-399, 2012.

[99] R. B. Inderka, Direkte Drehmomentregelung geschalteter Reluktanzantriebe: Zugl.: Aachen, Techn. Hochsch., Diss., 2002, vol. 29, Aachener Beiträge des ISEA, Aachen: Shaker, 2003.

[100] R. B. Inderka, and R. W. De Doncker, "DITC-direct instantaneous torque control of switched reluctance drives," in IEEE Transactions on Industry Applications 39.4, pp. 1046-1051, 2003.

[101] N. Fuengwarodsakul, Predictive PWM-based direct instantaneous torque control for switched reluctance machines: Zugl.: Aachen, Techn. Hochsch., Diss., 2007, vol. 45, Aachener Beiträge des ISEA, Aachen: Shaker, 2007.

[102] C. R. Neuhaus, N. Fuengwarodsakul, and R. W. De Doncker, "Predictive PWM-based direct instantaneous torque control of switched reluctance drives," in 2006 37th IEEE Power Electronics Specialists Conference. 2006, pp. 1-7.

[103] I. Ralev, F. Qi, B. Burkhart, A. Klein-Hessling, and R. W. De Doncker, "Impact of smooth torque control on the efficiency of a highspeed automotive SRM drive," in IEEE International Power Electronics and Motion Control Conference (PEMC). 2016, pp. 580-585.

[104] R. B. Inderka, Direkte Drehmomentregelung geschalteter Reluktanzantriebe, vol. 29, Aachener Beiträge des ISEA, Aachen: Shaker, 2003.

[105] A. Hofmann, F. Qi, T. Lange, and R. W. De Doncker, "The breathing mode-shape 0 : Is it the main acoustic issue in the PMSMs of today's electric vehicles?" in 17th International Conference on Electrical Machines and Systems (ICEMS). Oct. 2014, pp. 3067-3073.

[106] N. Kurihara, J. Bayless, and A. Chiba, "Noise and vibration reduction of switched reluctance motor with novel simplified current waveform to reduce force sum variation," in IEEE International Electric Machines and Drives Conference (IEMDC). May 2015, pp. 1794-1800.

[107] M. Takiguchi, H. Sugimoto, N. Kurihara, and A. Chiba, "Acoustic noise and vibration reduction of SRM by elimination of third harmonic component in sum of radial forces," in IEEE Transactions on Energy Conversion 30.3, pp. 883-891, Sept. 2015.

[108] N. Kurihara, J. Bayless, H. Sugimoto, and A. Chiba, "Noise reduction of switched reluctance motor with high number of poles by nov- el simplified current waveform at low speed and low torque region,' in IEEE Transactions on Industry Applications 52.4, pp. 3013-3021, Jul. 2016.

[109] B. Fahimi, G. Suresh, K. M. Rahman, and M. Ehsani, "Mitigation of acoustic noise and vibration in switched reluctance motor drive using neural network based current profiling," in Conference Record of IEEE Industry Applications Conference, vol. 1, Oct. 1998, pp.715722

[110] A. Klein-Hessling, F. Qi, I. Ralev, and R. W. De Doncker, “Acoustic optimization using vibration sensor feedback to the controller," in 2nd IEEE Annual Southern Power Electronics Conference (SPEC). Dec. 2016, pp. 1-5.

[111] T. J. E. Miller, Electronic control of switched reluctance machines, Oxford: NH Media, 2001.

[112] R. Krishnan, Switched reluctance motor drives: Modeling, simulation, analysis, design, and applications, Industrial electronics series. Boca Raton, Fla: CRC Press, 2001.

[113] M. Ehsani, and B. Fahimi, "Elimination of position sensors in switched reluctance motor drives: state of the art and future trends," in IEEE Transactions on Industrial Electronics 49.1, pp. 40-47, 2002.

[114] J. P. Lyons, S. R. MacMinn, and M. A. Preston, "Flux-current methods for SRM rotor position estimation," in Conference Record of the 1991 IEEE Industry Applications Society Annual Meeting. 1991, pp. 482-487.

[115] K. R. Thompson, P. P. Acarnley, and C. French, "Rotor position estimation in a switched reluctance drive using recursive least squares," in Industrial Electronics, IEEE Transactions on 47.2, pp. 368-379, 2000.

[116] G. G. Lopez, P. C. Kjaer, and T. J. E. Miller, "High-grade position estimation for SRM drives using flux linkage/current correction model," in IEEE Transactions on Industry Applications 35.4, pp 859-869, 1999.

[117] I. Ralev, B. Pariti, A. Klein-Hessling, and R. W. De Doncker, "Adopting a SOGI filter for flux linkage based rotor position sensing of switched reluctance machines," in 2017 IEEE International Electric Machines \& Drives Conference, to be published.

[118] P. P. Acarnley, R. J. Hill, and C. W. Hooper, "Detection of rotor position in stepping and switched motors by monitoring of current waveforms," in IEEE Transactions on Industrial Electronics IE-32.3, pp 215-222, 1985.

[119] G. G. Lopez, P. C. Kjaer, and T. J. E. Miller, "A new sensorless method for switched reluctance motor drives," in IEEE Transactions on Industry Applications 34.4, pp. 832-840, 1998.

[120] J. T. Bass, M. Ehsani, and T. J. E. Miller, "Robust torque control of switched-reluctance motors without a shaft-position sensor," in IEEE Transactions on Industrial Electronics IE-33.3, pp. 212-216, 1986.

[121] Freescale Semiconductor, 3-Phase Switched Reluctance (SR) Sensorless Motor Control Using a 56F80x, $56 F 8100$ or 56 F8300 Device.

[122] C. P. Weiss, A. Klein-Hessling, and R. W. De Doncker, "Discussion on control structure modifications using an FPGA for predictive DITC in switched reluctance machines regarding LUT resolution," in 2016 19th International Conference on Electrical Machines and Systems (ICEMS). 2016, pp. 1-6.

[123] Vorwerk. [Online]. Available: http://thermomix.vorwerk.de/home/

[124] Kobold VK 150. Vorwerk. [Online]. Available: www.vkdirect.co.uk

[125] Ametek Floorcare \& Speciality Motors. [Online]. Available: www. ametekfsm.com

[126] Dyson. [Online]. Available: www.dyson.de

[127] Picanol. [Online]. Available: www.picanol.be/en/machines/overview

[128] Beckman Coulter. [Online]. Available: www.beckmancoulter.com

[129] Nidec SR-Drives. [Online]. Available: http://www.srdrives.com/ train-air-con.shtml

[130] K. Buchholz. Valeo's electric supercharger targeted for 2015-16 production. Aug. 2012. [Online]. Available: http://articles.sae.org/11244/

[131] Valeo. [Online]. Available: www.valeo.com.

[132] Hilti. Hilti. Mar. 2017. [Online]. Available: www.hilti.de.

[133] S. Cummins, Reluctant Heroes, IVT International Off Highway Edition, 2012

[134] E. W. Fairall, B. Bilgin, and A. Emadi, "State-of-the-art highspeed 
switched reluctance machines," in IEEE International Electric Machines \& Drives Conference (IEMDC), pp. 1621-1627.

[135] J. B. Bartolo, M. Degano, J. Espina, and C. Gerada, "Design and initial testing of a high-speed $45-\mathrm{kW}$ switched reluctance drive for aerospace application," in IEEE Transactions on Industrial Electronics 64.2, pp. 988-997, 2017.

[136] A. M. Omekanda, "Switched reluctance machines for EV and HEV propulsion: State-of-the-art," in IEEE Workshop on Electrical Machines Design, Control and Diagnosis (WEMDCD), 2013, pp. 70-74.

[137] R. B. Inderka, S. von Malottki, C. Nizzola, B. Burkhart, A. Klein-Hessling, and R. W. De Doncker, "Cost Efficient Switched Reluctance Generator for Range Extension Unit," in 25th Aachen Colloquium Automobile and Engine Technology, 2016, pp. 1-14.

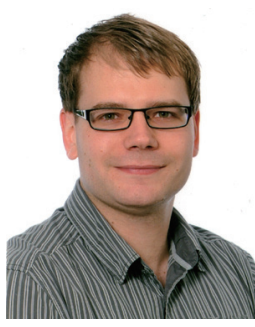

Bernhard Burkhart was born in Germany in 1985. He received the Diploma degree in electrical engineering from RWTH Aachen University of Aachen, Germany in 2011. Since November 2011 he has been a research associate at the Institute of Power Electronics and Electrical Drives (ISEA) at the RWTH Aachen University, Germany. His research interests include the field of switched reluctance machine design and control especially for generators.

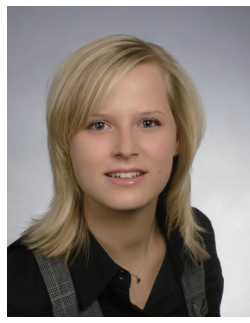

Annegret Klein-Hessling was born in Germany in 1986. She received the Diploma degree in electrical engineering and the Diploma degree in industrial engineering from the RWTH Aachen University, Germany, in 2012. Since October 2012 she has been a research associate at the Institute of Power Electronics and Electrical Drives (ISEA) at the RWTH Aachen University, Germany. Her research interests include the field of switched reluctance drives and their control.

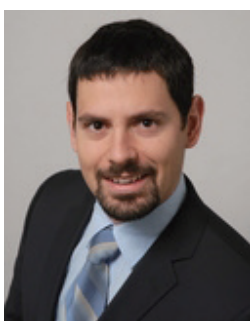

Iliya Ralev was born in Bulgaria in 1983. He received the Diploma degree in electrical engineering from RWTH Aachen University of Aachen, Germany in 2012. Since 2013 he has been a research associate at the Institute of Power Electronics and Electrical Drives (ISEA) at RWTH Aachen University, Germany. His research interests include control of rotating field machines and switched reluctance machines.

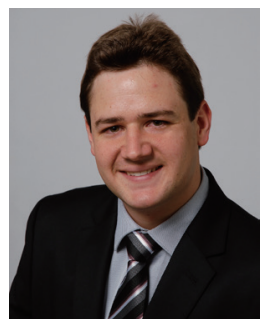

Claude P. Weiss was born in South Africa in 1985. He received the Diploma degree in electrical engineering in 2010 and the Diploma degree in business economics in 2012 from the RWTH Aachen University, Germany. Since 2012 he has worked as a research associate at the Institute of Power Electronics and Electrical Drives (ISEA) at RWTH Aachen University. His main research interest are design, modeling and control of electrical machines with special focus on reluctance drives.

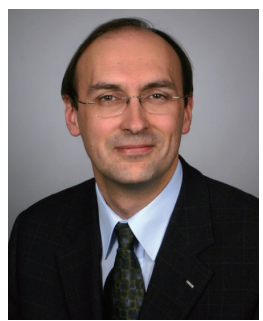

Rik W. De Doncker received the Ph.D. degree in electrical engineering from the Katholieke Universiteit Leuven, Leuven, Belgium, in 1986.

In 1987, he was appointed as a Visiting Associate Professor at the University of Wisconsin, Madison. After a short stay as an Adjunct Researcher with Interuniversity Microelectronics Centre, Leuven, he joined, in 1989, the Corporate Research and Development Center, General Electric Company, Schenectady, NY. In 1994, he joined Silicon Power Corporation, a former division of General Electric Inc., as the Vice President of Technology. In 1996, he became a Professor at RWTH Aachen University, Aachen, Germany, where he currently leads the Institute for Power Electronics and Electrical Drives. Since 2006, he has been the Director of the E.ON Energy Research Center, RWTH Aachen University. Dr. De Doncker was the President of the IEEE Power Electronics Society (PELS) in 2005 and 2006. He was the founding Chairman of the German IEEE Industry Applications Society PELS Joint Chapter. In 2002, he was the recipient of the IEEE IAS Outstanding Achievement Award. In 2008, he received the IEEE PES Nari Hingorani Custom Power Award. In 2009, he led a VDE/ETG Task Force on Electric Vehicles. In 2010, he received an honorary doctor degree of TU Riga, Latvia. In 2013, he received the IEEE William E. Newell Power Electronics Award. 